\title{
Analysis of Traveling Behavior of Nut Coke Particles in Bell-type Charging Process of Blast Furnace by Using Discrete Element Method
}

\author{
Hiroshi MIO, ${ }^{1,2)}$ Satoshi KOMATSUKI, ${ }^{3)}$ Masatoshi AKASHI, ${ }^{3)}$ Atsuko SHIMOSAKA, ${ }^{3)}$ \\ Yoshiyuki SHIRAKAWA, ${ }^{3)}$ Jusuke HIDAKA, ${ }^{3)}$ Masatomo KADOWAKI, ${ }^{4)}$ Hirokazu YOKOYAMA, ${ }^{4)}$ \\ Shinroku MATSUZAKI ${ }^{4)}$ and Kazuya KUNITOMO ${ }^{4)}$
}

1) Research Center for Advanced Science and Technology, Doshisha University, 1-3 Tatara-miyakodani, Kyotanabe, Kyoto 6100321 Japan. $\quad$ 2) Kyoto Fine Particle Technology, Keihanna Interaction Plaza Inc., 1-7 Hikaridai, Seika-cho, Soraku-gun, Kyoto 619-0237 Japan. $\quad 3$ 3) Department of Chemical Engineering and Materials Science, Doshisha University, 1-3 Tataramiyakodani, Kyotanabe, Kyoto 610-0321 Japan. 4) Environmental and Process Technology Center, Nippon Steel Corporation, 20-1 Shintomi, Futtsu, Chiba 293-8511 Japan.

(Received on November 2, 2009; accepted on February 17, 2010)

\begin{abstract}
The objective of this paper is to analyze the particle behavior in bell-type charging process of actual blast furnace by using Discrete Element Method (DEM). The circumferential balance of charged mass in the quad-hopper and the effect of the nut coke particle position in the quad-hopper on the traveling behavior and the segregation were discussed. The mass flow rate discharged from the rotating chute was fluctuated with the time, and the peak values gave when the directions of the chute movement became same as the one of the conveyor. It leads to the unbalance of charged particles in each part of the quad-hopper. The nut coke moved to the upward in the sintered ore particle layer during traveling to large bell from the quad-hopper due to the particle segregation, when they were segregated at the bottom of hopper. However their relative positions moved downward when they were segregated at the top, because the time for starting discharging of nut coke became faster. The installation of the damper at the way to the small bell from the hopper affects on the circumferential balance of mass of nut coke. Most of nut coke particles were charged at near the wall of blast furnace, and the small peak of the distribution of its specific charged mass was seen around $3.0 \mathrm{~m}$ in the radial distance from the center, it caused by the particle segregation during flowing on the particle layer. The relative radial distribution of the nut coke particles wasn't affected by their positions in the large bell and the total mass. Thus, keeping the circumferential balance of nut coke mass in the large bell is very important. The position of nut coke particle didn't affect on the segregation of sintered ore. The radial distributions of relative charged mass for all conditions were quite similar.
\end{abstract}

KEY WORDS: bell-type blast furnace; nut coke; segregation; charging process; simulation; Discrete Element Method.

\section{Introduction}

A blast furnace is a reactor for reducing the iron ore to pig-iron, and it has been traditionally used in the world. The iron ore and the coke particles are charged in the blast furnace with alternating layers, and the gas having high temperature is blown from the tuyeres. A great effort has been paid toward the improvement in the productivity, and mixing the nut coke particles in the burden of iron ore is particularly employed to enhance the efficiency of reductive reaction of iron ore by increasing the contact frequency between the iron ore and the coke particles. ${ }^{1-5)}$ The size of nut coke particle is generally same as that of iron ore, however the density of coke is much smaller. Thus, the particle segregation caused by the density difference takes place during delivering to the blast furnace. There are a lot of storages, bunkers, conveyors and chutes on the way to the blast furnace, and the particles are usually segregated in the repetitive charging and discharging processes. People want to control the charging area of the nut coke particles at the inefficient area in the blast furnace, therefore it is necessary to clear the particle segregation during traveling. The computational simulation using Discrete Element Method $^{6)}$ (DEM) is one of the most useful tools for the analysis and the visualization of the particle behavior in the ironmaking process. Some researches are already going on. ${ }^{7-9)}$ The authors have been trying to analyze the particle segregation during the charging process. Before doing the simulation of the granular flow in the ironmaking process, the effect of the particles shape on the granular behavior had to be solved, and the authors had proposed the method for the considering the particle shape by using the distributed values of rolling friction. ${ }^{10}$ ) This method gave the good agreement with the experimental results of the particle 
segregation in the laboratory-scale chute, and it was applied to the analysis of the particle segregation during charging process of bell-less type blast furnace. ${ }^{11)}$

In this paper, the charging process of the bell-type blast furnace was modeled to investigate the particle behavior and its segregation during traveling to the blast furnace by using DEM. The charging processes from the top conveyor, rotating chute, quad-hopper, small bell and large bell to the blast furnace were modeled. The circumferential balance of charged particles in the quad-hopper and the effect of the position of nut coke particle in the quad-hopper on the traveling behavior and the segregation in the blast furnace were mainly discussed.

\section{Simulation}

\subsection{Discrete Element Method}

Discrete Element Method (DEM) ${ }^{6}$ ) is one of the most popular and reliable simulation methods for the numerical analysis of solid particle behavior. This simulation method consists of the idea of determining the kinematic force to each finite-sized particle. The contact between two particles is given by Voigt model, which consists of a spring-dashpot and a slider for friction in the tangential component. The contact forces, $\mathbf{F}_{\mathrm{n}}$ (compressive force) and $\mathbf{F}_{\mathrm{t}}$, (shear force) are calculated from following equations.

$$
\begin{aligned}
& \mathbf{F}_{\mathrm{n}, i j}=\left(K_{n} \Delta u_{n, i j}+\eta_{n} \frac{\Delta u_{n, i j}}{\Delta t}\right) \mathbf{n}_{i j} \ldots \ldots . . \\
& \mathbf{F}_{\mathrm{t}, i j}=\min \left\{\mu\left|\mathbf{F}_{n, i j}\right| \mathbf{t}_{i j},\left[K_{t}\left(\Delta u_{t, i j}+\Delta \phi_{i j}\right)\right.\right. \\
&\left.\left.+\eta_{t}\left(\frac{\Delta u_{t, i j}+\Delta \phi_{i j}}{\Delta t}\right)\right] \mathbf{t}_{i j}\right\} \ldots \ldots \ldots . . . . .
\end{aligned}
$$

Where, $K$ and $\eta$ denote the spring and the damping coefficients. $\Delta u$ and $\Delta \phi$ are a relative translational displacement of gravitational center between two particles in contact and a relative displacement at the contact point caused by the particle rotation. $\mu$ is the frictional coefficient (particleparticle: 0.43 , particle-wall: 0.58 ). The frictional coefficients of particle were estimated by shearing test of the single particles and comparing particle behavior, and the particle behaviors using these values had been already validated with the experimental work, which was reported. ${ }^{10)}$ These values had been already applied to the analysis of charging behavior in the rotating chute of the blast furnace, ${ }^{11)}$ and it had given fruitful information. Thus, these values were used in this work. $\mathbf{n}_{i j}$ and $\mathbf{t}_{i j}$ denote the unit vector from the $i$-th particle to the $j$-th one in the normal and the tangential components. The subscript $\mathrm{n}$ and $\mathrm{t}$ also denote the normal and the tangential components. The translational and rotational motions of each particle are updated by following equations.

$$
\dot{\mathbf{v}}=\frac{\sum \mathbf{F}}{m}+\mathbf{g}
$$

$$
\dot{\boldsymbol{\omega}}=\frac{\sum \mathbf{M}}{I}
$$

Where, $\mathbf{v}$ is the vector of a particle velocity, $\mathbf{F}$ is the contact force acting on a particle, $m$ and $\mathbf{g}$ mean the mass of a particle and gravitational acceleration, $\boldsymbol{\omega}$ is the vector of angular velocity, $\mathbf{M}$ and $I$ denote the moment caused by the tangential force and the moment of inertia. The shape of particle in DEM is usually assumed to be spherical due to the ease of contact detection or calculation of contact force, although the shapes of particles in the ironmaking process are completely irregular. Thus, its effect on the particle motion must be considered in DEM by setting the proper rolling friction for each particle, and it is given by Eq. (5). ${ }^{10)}$

$$
\mathbf{M}_{r, i}=-\frac{3}{8} \alpha_{i} b\left|\mathbf{F}_{n}\right| \frac{\boldsymbol{\omega}_{i}}{\left|\boldsymbol{\omega}_{i}\right|}
$$

Where, $b$ is a radius of contact area, and $\alpha_{i}$ denotes the coefficient of rolling friction. Every particle has individual value of $\alpha_{i}$ because the particle shapes are totally different from each other. Its distribution is related with the rollability of particle. ${ }^{10)}$ The traveling distance of sintered ore particle, when it dropped on the oblique plate, was measured. The discharging velocity at the outlet of chute and the discharging time from the hopper were compared between the experimental result and simulated one under different rolling friction. Then, the rolling friction in DEM was related to the rollability of particle. The method for considering particle shape by setting the individual rolling friction had given the significant agreement with the experimental results, ${ }^{10)}$ therefore, this method was applied to the present work.

\subsection{Simulation Condition}

The particle behaviors in three stages of charging process of the bell-type blast furnace were simulated in this work.

- Charging to the quad-hopper from the top conveyor via the rotating chute;

- Charging to the large bell via the small bell from one of the quad-hopper;

- Charging into the blast furnace from the large bell. The traveling behavior and segregation of the nut coke particle in the sintered ore particle bed were mainly discussed.

\subsubsection{Analysis of Circumferential Balance of Charged Particles in the Quad-hopper}

Forty tons of sintered ore particles (number of particles, $\left.n_{\text {ore }}=709224\right)$ and $356 \mathrm{~kg}$ of nut coke particles $\left(n_{\text {nut }}=3729\right)$ were positioned on the conveyer, and they were conveyed under $1.4 \mathrm{~m} / \mathrm{s}$. The particles were charged to the quad-hopper with flowing thought the rotating chute, which was rotated at $13 \mathrm{rpm}$ (one of the actual operational conditions), and the schematic diagram of the system is shown in Fig. 1. The nut coke particles were located at the head of particles layer on the conveyor, and the sintered ore particles were positioned at back of nut coke particles. The sintered ore particles on the conveyer didn't have the particle size segregation. Tables $\mathbf{1}$ and $\mathbf{2}$ show the particle conditions of sintered ore and the nut coke, and all of particles were enlarged relatively 3 times larger than those of actual ones. 


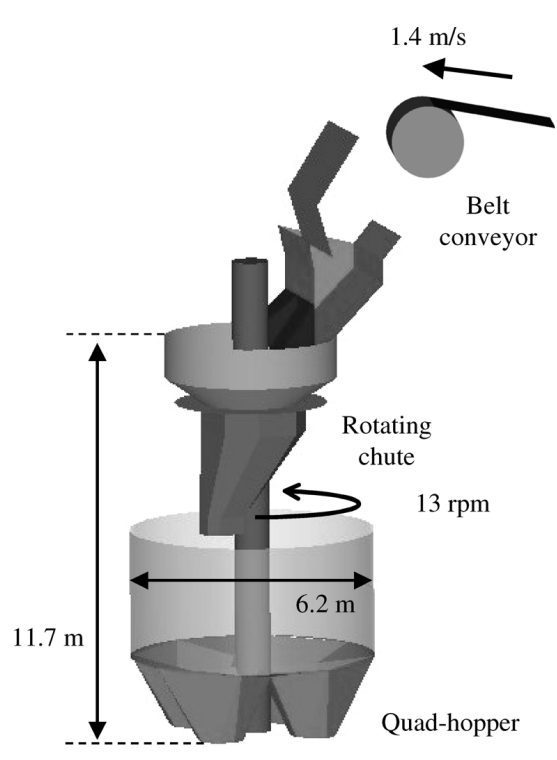

Fig. 1. Schematic diagram of top conveyor, rotating chute and quad-hopper.

Table 1. Condition of sintered ore particles for the simulation of charging to the quad-hopper.

\begin{tabular}{ccc}
\hline $\begin{array}{c}\text { Particle diameter } \\
{[\mathrm{mm}]}\end{array}$ & $\begin{array}{c}\text { Number of particles } \\
{[-]}\end{array}$ & $\begin{array}{c}\text { Mass ratio } \\
{[\text { mass\%] }}\end{array}$ \\
\hline \hline 22.5 & 592840 & 29.7 \\
37.5 & 79504 & 18.4 \\
52.5 & 19984 & 12.7 \\
67.5 & 10904 & 14.7 \\
97.5 & 5992 & 24.4 \\
\hline
\end{tabular}

Table 2. Condition of nut coke particles.

\begin{tabular}{ccc}
\hline $\begin{array}{c}\text { Particle diameter } \\
{[\mathrm{mm}]}\end{array}$ & $\begin{array}{c}\text { Number of particles } \\
{[-]}\end{array}$ & $\begin{array}{c}\text { Mass ratio } \\
\text { [mass\%] }\end{array}$ \\
\hline \hline 22.5 & 1081 & 1.9 \\
37.5 & 885 & 7.2 \\
52.5 & 833 & 18.6 \\
67.5 & 636 & 30.2 \\
97.5 & 294 & 42.1 \\
\hline
\end{tabular}

The particle size range of nut coke was same as that of sintered ore, however the mass fraction was different. Young's modules, Poisson's ratio and the density of these particles are tabulated in Table 3, and $\Delta t$ was $2.0 \mu \mathrm{s}$. The circumferential balance of the charged particles in the quad-hopper was analyzed.

\subsubsection{Analysis of Nut Coke Traveling Behavior to the Large Bell via the Small Bell}

The effect of the position of the nut coke particles in the quad-hopper on their segregation during traveling to the large bell was discussed. One of the quad-hopper was simulated in this analysis because the geometry of this system has the similarity in every 90 degrees, hence the particles were charged to the area of a quarter of the bell. The side walls were set at 0 and 90 degrees in angular position, and these walls had the same frictional coefficient of particles. Three initial conditions of $356 \mathrm{~kg}$ of nut coke particles in one of quad-hopper were analyzed.

- Condition 1: segregated at the bottom;
Table 3. Material properties in DEM.

\begin{tabular}{llcc}
\hline & & Sintered ore & Coke \\
\hline \hline Young's modulus & {$[\mathrm{GPa}]$} & 35 & 5.4 \\
Poission's ratio & {$[-]$} & 0.25 & 0.22 \\
Density & {$\left[\mathrm{kg} / \mathrm{m}^{3}\right]$} & 3300 & 1050 \\
\hline
\end{tabular}

Table 4. Condition of sintered ore particles for the simulation of the traveling behavior from the quad-hopper to the blast furnace.

\begin{tabular}{ccc}
\hline $\begin{array}{c}\text { Particle diameter } \\
{[\mathrm{mm}]}\end{array}$ & $\begin{array}{c}\text { Number of particles } \\
{[-]}\end{array}$ & $\begin{array}{c}\text { Mass ratio } \\
{[\text { mass\%] }}\end{array}$ \\
\hline \hline 22.5 & 355345 & 37.3 \\
37.5 & 42811 & 20.8 \\
52.5 & 10759 & 14.3 \\
67.5 & 5874 & 16.6 \\
97.5 & 1276 & 10.9 \\
\hline
\end{tabular}

- Condition 2: segregated at the top;

- Condition 3: completely mixed in the sintered ore particles.

The particles size distribution of nut coke was same as Table 2. Table 4 shows the condition of sintered ore particles ( 17.75 tons, $\left.n_{\text {ore }}=416065\right)$, which were charged in one of the quad-hopper. The sintered ore particles were wellmixed in all conditions, and there is no segregation of the sintered ore in the hopper. A damper having 45 degrees in inclination angle was installed between the outlet of the quad-hopper and the small bell. The distance between the outlet and the bottom of large bell was $14.5 \mathrm{~m}$. At first, the particles were charged to the small bell, and they were discharged from there after all particles were settled well in the small bell.

\subsubsection{Analysis of Particle Charging Behavior into the Blast Furnace}

The particles were charged into the blast furnace from the large bell to investigate the particle segregation during charging. The particles, which were charged to the large bell in the previous section, were used; i.e. having three different nut coke positions in the quad-hopper. The coke layer was arranged at the top of the blast furnace, and the sintered ore layer under the coke was not arranged, but the oblique plate having the same frictional coefficient as the particles was set instead of the ore layer. The particles sizes of coke were 100 to $200 \mathrm{~mm}$ in diameter, and they were positioned randomly (no size segregation) in the layer having 32 degrees of the inclination angle. The radii of the large bell and the blast furnace were $4.5 \mathrm{~m}$ and $5.5 \mathrm{~m}$. The coke layer didn't descend during charging, and the effect of gas flow was not considered. The movable armor was not used in this analysis.

\section{Results and Discussions}

\subsection{Analysis of Circumferential Balance of Charged Particles in the Quad-hopper}

Figure 2 shows the snapshots of particle charging behavior from the conveyor to the quad-hopper. The particle colors of the sintered ore are designated the different particle size; yellow: $97.5 \mathrm{~mm}$, red: $67.5 \mathrm{~mm}$, pink: $52.5 \mathrm{~mm}$, green: 


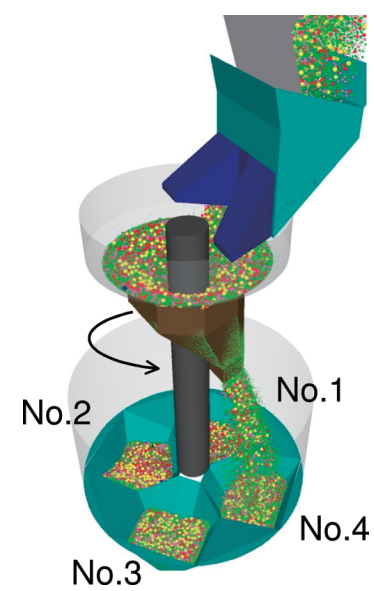

Fig. 2. Snapshot of particle behavior charging to the quad-hopper.

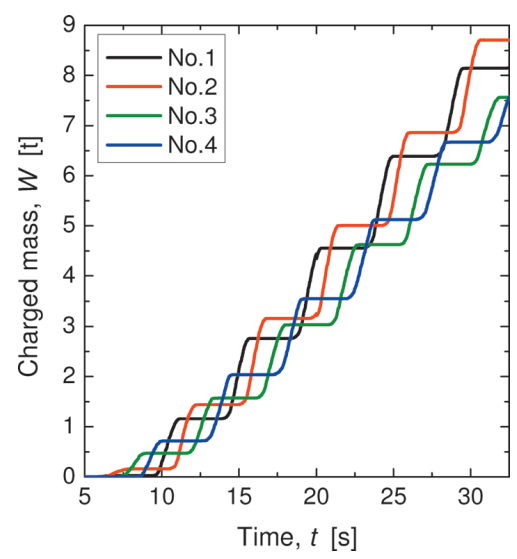

Fig. 3. Time changes of mass of charge particles in each part of quad-hopper.

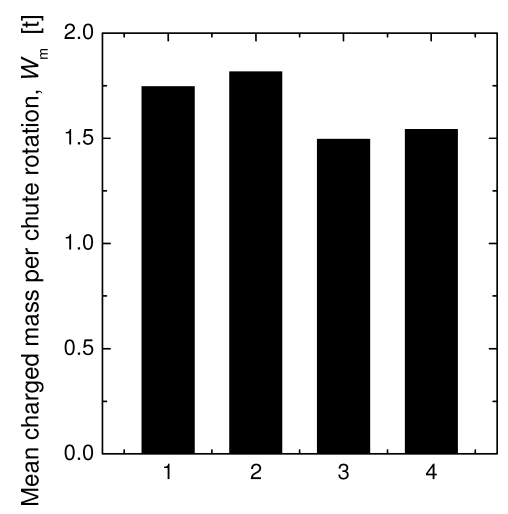

Fig. 4. Mean charged mass per chute rotation.

$37.5 \mathrm{~mm}$ and light green: $22.5 \mathrm{~mm}$, on the other hand, the nut cokes were blue, irrespective of their size. Some particles stay at the top of rotating chute, and others are being discharged from there. Figure 3 shows the time changes of the mass of charged particles, $W$, in each hopper. The hopper number refers to Fig. 2. $W$ increases stepwise with increasing the time due to the chute rotation. $W$ for No. 2hopper seems to be larger than $W$ of others, on the other hand, the one for No. 3-hopper is smaller. Figure 4 shows the mean charged mass per chute rotation, $W_{\mathrm{m}}$. It is found that $W_{\mathrm{m}}$ for No. 2-hopper is the largest, and $W_{\mathrm{m}}$ for No. 3 is $17.5 \%$ smaller than that of No. 2. Figure 5 shows the relation between the mass flow rate discharged from the rotat-

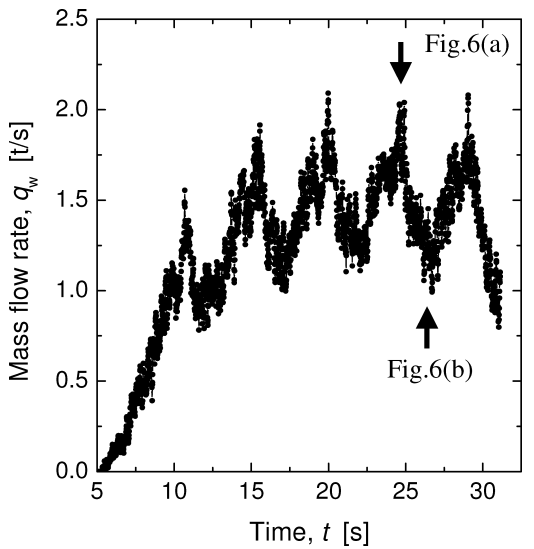

Fig. 5. Relation between the mass flow rate discharged from the rotating chute and the time.
0

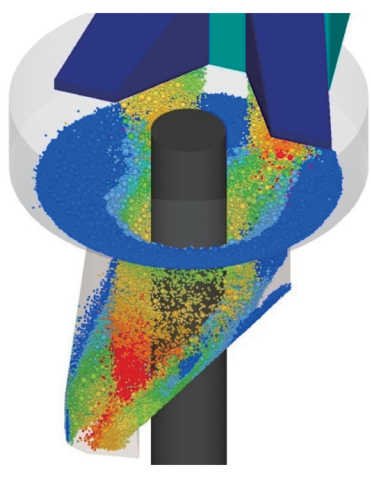

(a) Over No.2 hopper
$0.7 \mathrm{~m} / \mathrm{s}$

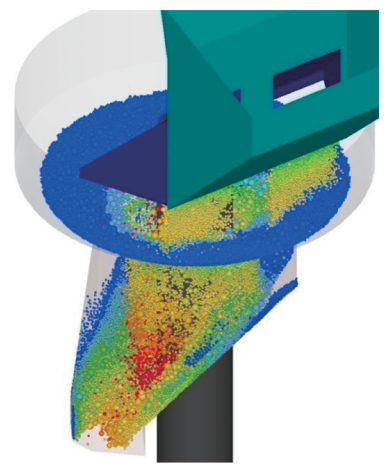

(b) Over No.3 hopper
Fig. 6. Snapshots of particle velocity in the chute.

ing chute, $q_{\mathrm{w}}$, and the time. $q_{\mathrm{w}}$ is fluctuated with the time very much, and the peaks are given when the chute is over the No. 2-hopper. When the chute is over the No. 2-hopper, the direction of the chute movement becomes same as the one of conveyor. Thus, the reduction of particle velocity is less, and the particles are easy to pass through the chute. On the other hand, $q_{\mathrm{w}}$ becomes smaller when the chute comes over the No. 3-hopper, because the particle movement and the chute rotation becomes counter direction. Figure 6 shows the snapshots of particles in the rotating chute under two chute positions; i.e. (a) over No. 2-hopper, (b) over the No. 3-hopper, and the particles are colorized by their velocities. It is confirmed that the particles in Fig. 6(a) have larger velocity, hence the particles are easy to be discharged from the chute. The stagnant zones are also seen in these figures, i.e. the top or inside of the chute. Figure 7 shows the time changes of mass of charged nut coke particles in four areas of quad-hopper. The mass increases stepwise due to the chute rotation like in Fig. 3, however the increase of each rotation decreases with increasing the time. The nut coke particles were positioned at the head of conveyer, thus the initial increase of the charged mass in the quad-hopper was affected by this condition strongly. The mass of each hopper also has the different value. It is affected by the initial increase caused from the nut coke posi- 


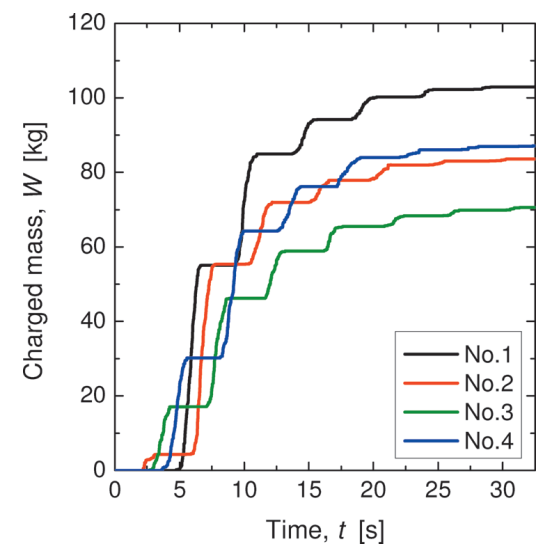

Fig. 7. Time changes of mass of charged nut coke particles in each part of quad-hopper.

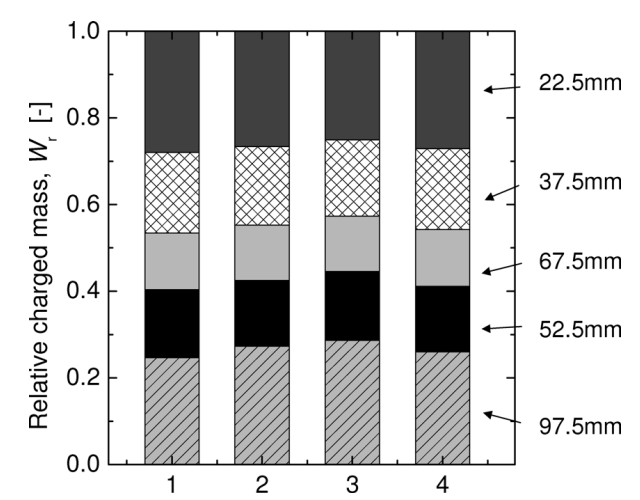

Fig. 8. Relative charged mass of sintered ore particles in each hopper.

tion on the conveyor, because all nut coke particles came into the chute within $4 \mathrm{~s}$ compared with $4.6 \mathrm{~s}$ for one chute rotation. Some of them remain in the top of rotating chute, and they are not discharged from the chute immediately, thus it is difficult to make a balance of the mass of nut coke in each part of quad-hopper in this condition. Changing the position on the conveyor would be necessary. Figure 8 shows the relative charged mass of sintered ore particles in each hopper. The fractions of the largest and the smallest particles for each hopper are slightly different, because of the stagnant particles at the top or the difference of the particle velocity in the chute. To improve the balance of the charged particles in each hopper, it is necessary to clear the stagnant zone at the top/inside of the rotating chute, and the mass flow rate discharged from the chute should be made stable. However, most of the values are very similar to the initial mixing ratio, therefore the analysis of the traveling behavior from the quad-hopper to the blast furnace would be carried out using only one of the quad-hopper.

\subsection{Analysis of Nut Coke Traveling Behavior to the Large Bell via the Small Bell}

Figure 9 shows the snapshots of particle behavior during charging to the small bell from the one of quad-hopper under Condition 1 (nut coke: bottom). The particles, which are discharged from the hopper, hit on the damper, slide on the small bell surface and are settled in the small bell. The nut coke particles are colorized with blue, and they are segregated at the bottom of the small bell because they posi-

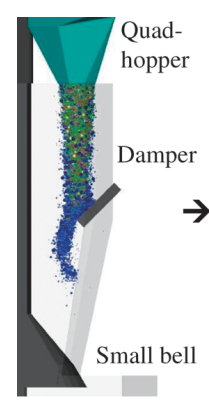

$1.0 \mathrm{~s}$

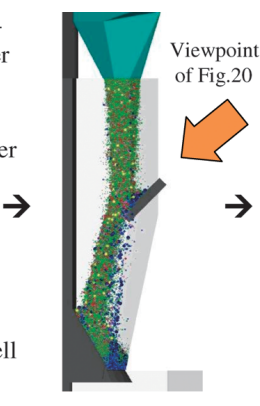

$2.0 \mathrm{~s}$
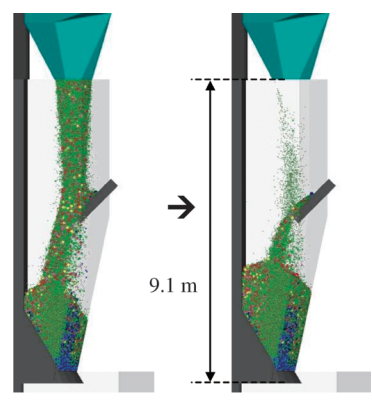

$4.0 \mathrm{~s}$
$6.0 \mathrm{~s}$
Fig. 9. Snapshots of particle behavior during charging to the small bell from the one of quad-hopper under Condition 1.

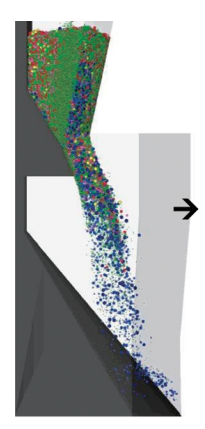

$1.5 \mathrm{~s}$

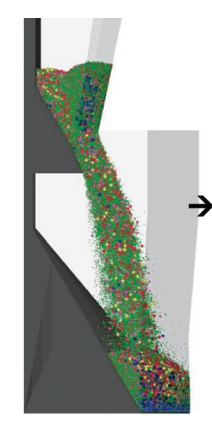

$6.0 \mathrm{~s}$

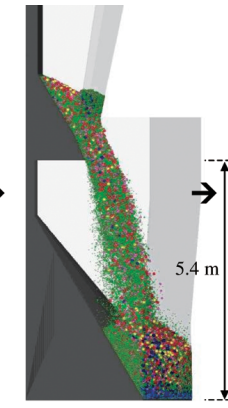

$9.0 \mathrm{~s}$

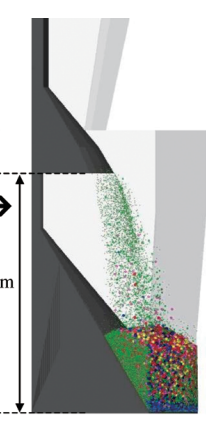

$12.0 \mathrm{~s}$
Fig. 10. Snapshots of particle charging behavior from the small bell to the large bell under Condition 1 .

tioned at the bottom of the quad-hopper, and they were discharged at the early stage. The ore particles are also colored by their sizes (refer to Fig. 2). Figure $\mathbf{1 0}$ shows the snapshots of particle charging behavior from the small bell to the large bell under Condition 1. It is seen that the smallest particles are discharged from the small bell at the end because they have large interaction from the bell surface caused by the particle size segregation. The nut coke particles are settled at the bottom of the large bell as similar to the case of the small bell. Figure 11 shows the snapshots of the cross section of quad-hopper, small bell and large bell. It is found from these snapshots that the most of nut coke particles were settled at the bottom, however a few particles moved upward during traveling to the large bell. Figure 12 shows the relation between the relative charged volume of nut coke, $V_{\text {coke }} / V_{0}\left(V_{0}=V_{\text {coke }}+V_{\text {ore }}\right)$, and the relative vertical position, $Z_{\mathrm{r}}$. $Z_{\mathrm{r}}$ was given by normalizing the particle position by the maximum height of charged bed, and $V_{\text {coke }} / V_{0}$ were divided in 10 areas according to $Z_{\mathrm{r}}$. The nut coke particles were not positioned at $Z_{\mathrm{r}}>0.25$ in the quad-hopper. However, a few particles are present at the top of the particle bed in the large bell after traveled. Because the density of nut coke is about one-third of that of sintered ore, they are segregated easily during flowing. Figures 13 and 14 shows the snapshots of the cross section of quad-hopper, small or large bells, and the relation between $V_{\text {coke }} / V_{0}$ and $Z_{\mathrm{r}}$ under Condition 2. The most of nut coke particles in the small bell are settled at below the top surface, even though all nut coke were segregated at the top of the particle bed in the quad-hopper. The nut coke position shifts downward with traveling to the large bell. Figure 15 shows the snapshot of the particles in the hopper, which are colored by the 


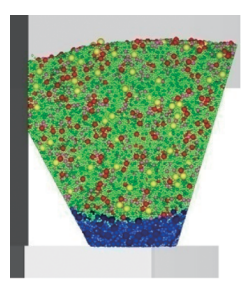

(a) Quad-hopper

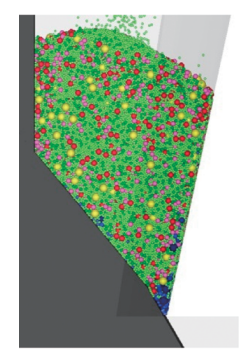

(b) Small bell

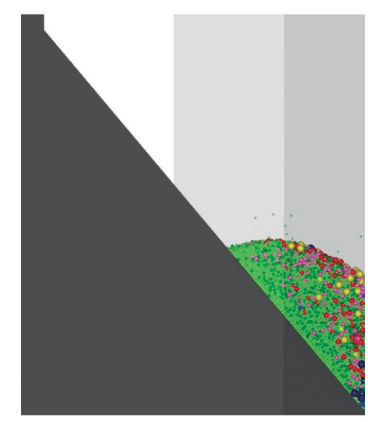

(c) Large bell

Fig. 11. Snapshots of cross section of particle bed under Condition 1 .

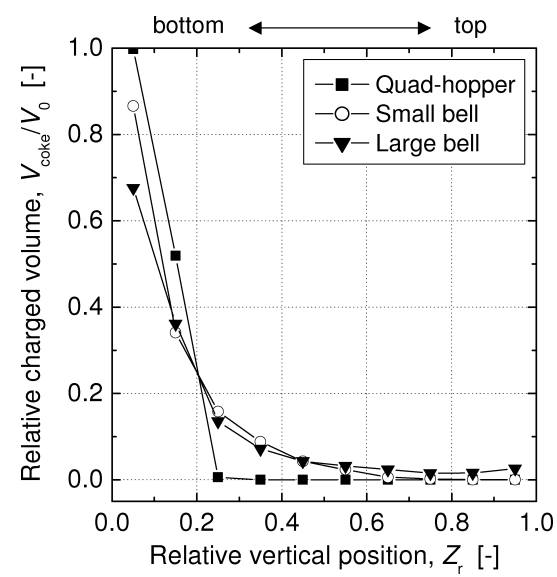

Fig. 12. Relation between the relative charged volume of nut coke and the relative vertical position under Condition 1.

discharged time. The time for passing though the outlet was recorded and it was normalized by the discharging time of all particles, $t_{\mathrm{d}}$. It is found that some nut coke particles, which were located at the center of the hopper, started to be discharged at around $0.5 t_{\mathrm{d}}$. Figure 16 also shows the discharging time mapping in the small bell. The time for starting discharging of nut coke particle becomes faster. This is the reason why the position of nut coke particle moved downward. Thus, the nut coke traveling behavior is affected by the discharging time rather than the particle segregation in this case. Of course the segregation took place during

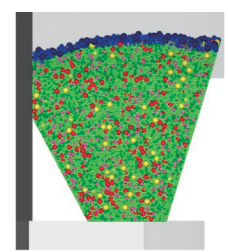

(a) Quad-hopper

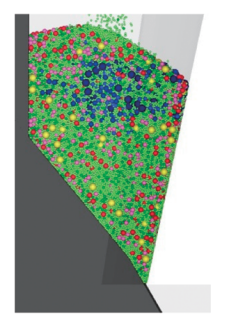

(b) Small bell

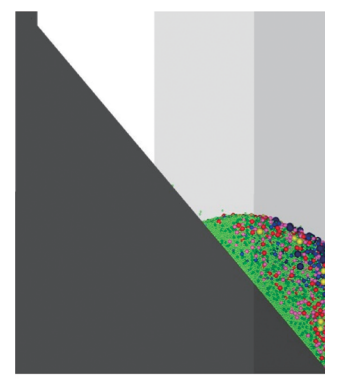

(c) Large bell

Fig. 13. Snapshots of cross section of particle bed under Condition 2 .

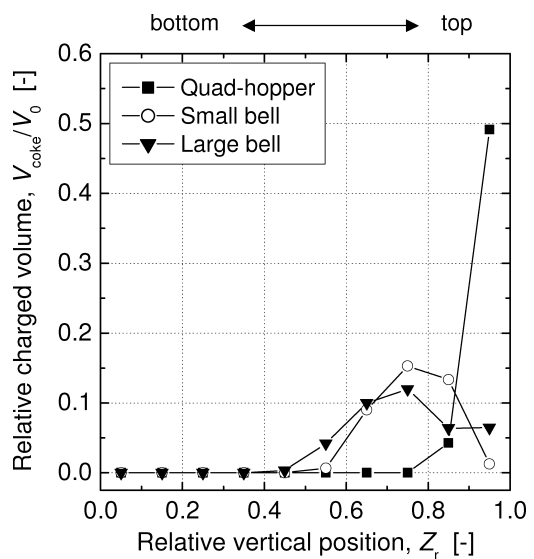

Fig. 14. Relation between the relative charged volume of nut coke and the relative vertical position under Condition 2 .

traveling from the small bell to large one, $V_{\text {coke }} / V_{0}$ at $Z_{\mathrm{r}}=0.95$ of large bell increased from the value of small bell. This increase was caused by the segregation of nut coke during flowing with sintered ore particles. Figures $\mathbf{1 7}$ and 18 show the snapshots and the relative charged volume for Condition 3. Although a few nut coke particles moved upward during traveling from the small bell to the large bell, the serious segregation of nut coke isn't seen in this condition because they were mixed well with the sintered ore particles in the hopper. In the large bell, the small sintered ore particles segregated near the bell surface, because the most of particles slid on the bell surface.

Figure 19 shows the charged mass of nut coke particles in a circumferential direction of the small bell under three conditions. The particles are divided in six areas. It is note- 

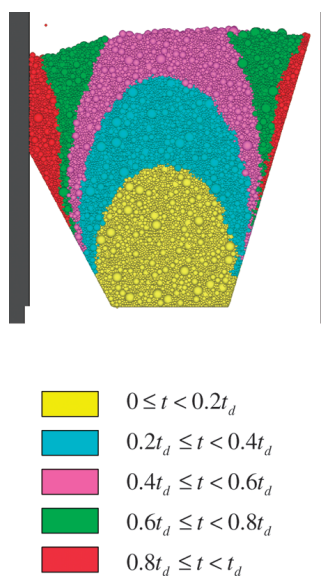

Fig. 15. Mapping of particle discharged time from the hopper.
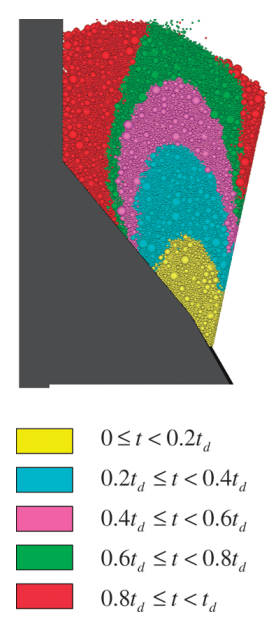

Fig. 16. Mapping of particle discharged time from the small bell.

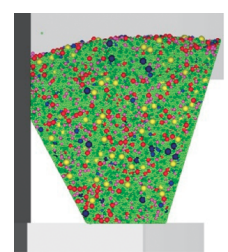

(a) Quad-hopper

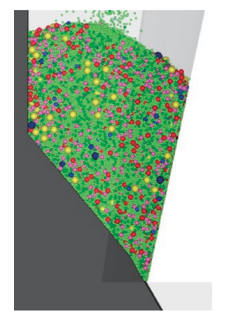

(b) Small bell

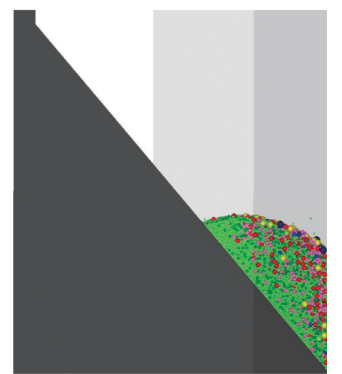

(c) Large bell

Fig. 17. Snapshots of cross section of particle bed under Condition 3 .

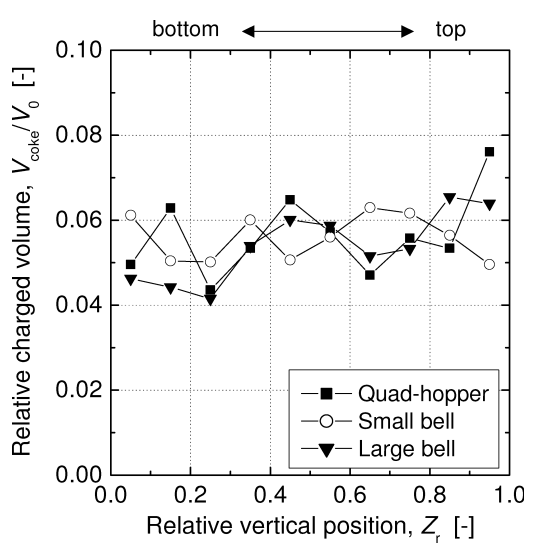

Fig. 18. Relation between the relative charged volume of nut coke and the relative vertical position under Condition 3. worthy about Fig. 19 that a lot of nut coke particles are positioned at $0-15$ and 75-90 degrees in Condition 1, on the other hand, they are segregated at 30-60 degrees in Condition 2. The tendencies of the nut coke location are completely different, and the position of nut coke in the quadhopper would affect on the segregation during traveling to the small bell. Figure 20 shows the snapshot of the particle behavior during impacting on the damper under Condition 1. The viewpoint of this figure is referred to Fig. 9. The particles flow is widened when the particles hit on the damper, and they seemed to start to be settled from the areas around both sides. The nut coke particles were posi-

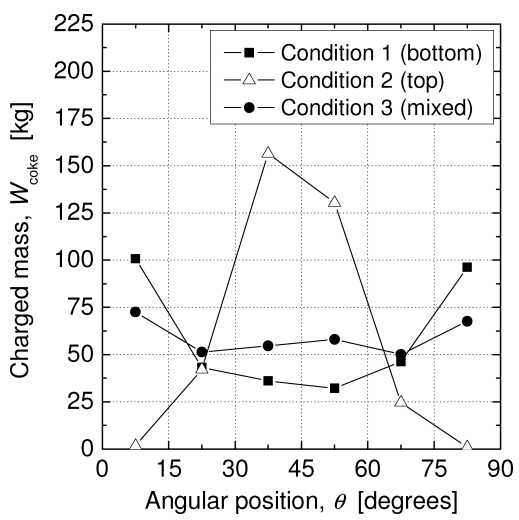

Fig. 19. Charge masses of nut coke particles in a circumferential direction of the small bell.

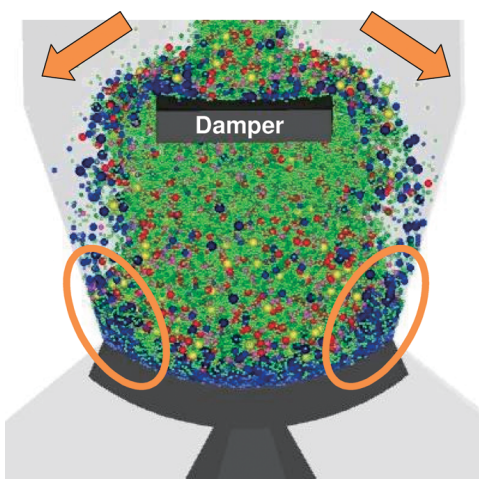

Fig. 20. Snapshot of particle behavior during impacting on the damper under Condition 1.

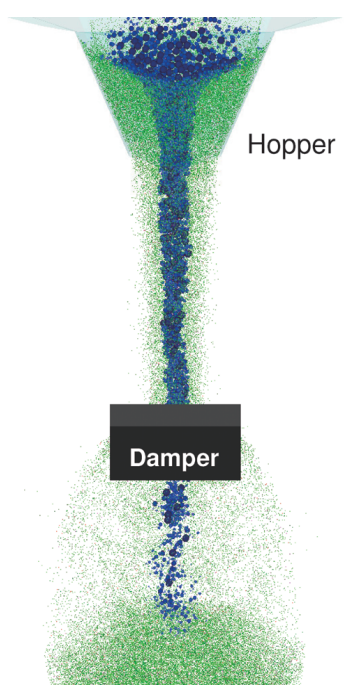

Fig. 21. Snapshot of particle flow under Condition 2.

tioned at the bottom of the hopper, thus they were widened easily and settled mainly at $0-15$ and 75-90 degrees. According to discharging timing map of the hopper as shown in Fig. 15, the nut coke particles were discharged from the middle period under Condition 2, and they pass through the center of the outlet. Figure 21 shows the snapshot of particle flow under Condition 2, and all of the sintered ore particles were drawn much smaller than the normal size to be able to see the nut coke particles clearly. It is seen that the 
nut coke particles are discharged from the hopper with narrow flow, and they are not widened by impacting on the damper because the sintered ore particles are surrounding. This is the reason why the most of them positioned at under the damper. The particle behavior under Condition 3 is affected by only the side wall, which was installed at boundary in this calculation, when particle are well mixed in the hopper. Although the masses of the nut coke at $0-15$ and 75-90 degrees are large slightly, the particle segregation seems to be a little. Figure $\mathbf{2 2}$ shows the charged mass of nut coke in the large bell. The values are quite similar to those in Fig. 19, because the particles were just falling down from the small bell, and the particles hardly moved to circumferential direction. Therefore, the circumferential balance must be controlled before charging to the large bell. Figure 23 shows the relation between the relative charged mass of different sizes of sintered ore and the angular position in the large bell. The smallest particles are settled mainly around 15-75 degrees, because the smallest particles were segregated at the damper surface when they hit on it (see Fig. 20). Thus, they fell down at the extended line of the damper edge. On the other hand, the larger particles (especially 52.5 and $67.5 \mathrm{~mm}$, the initial volume of largest particles is too small, then it can not be seen the difference between the angular positions) are positioned more at $0-15$ and $75-90$ degrees. The reason of this phenomenon is same as the case of smallest particles; i.e. it is caused by the segregation at the damper surface. The most of larger particles moves at the upper area of the granular flow during sliding on the damper, thus their flows tend to be widened easily. Therefore, it is found that the installation of

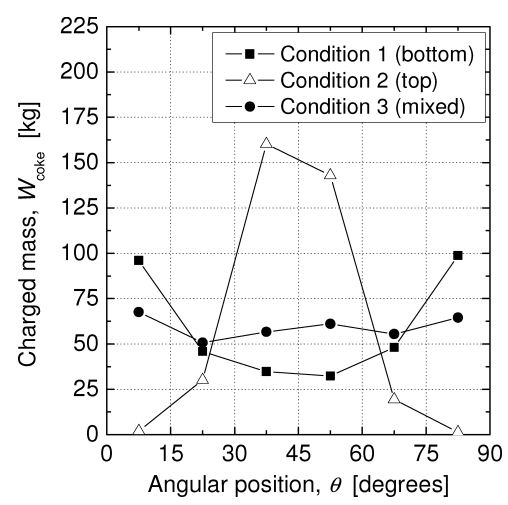

Fig. 22. Charge masses of nut coke particles in a circumferential direction of the large bell.

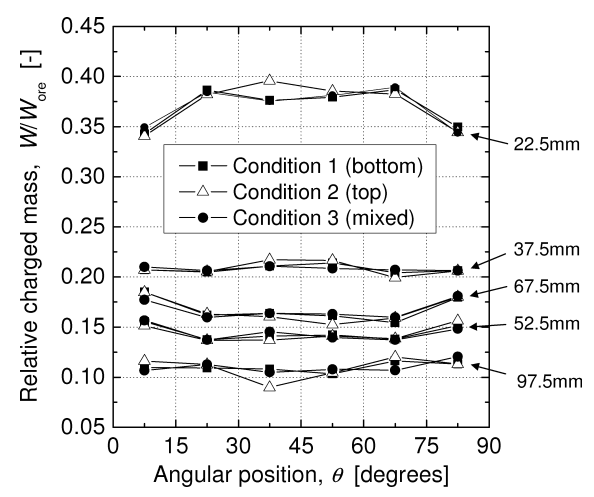

Fig. 23. Relation between the relative charged mass of sintered ore particles and the angular position in the large bell. the damper at the way to the small bell from the hopper affects on the particle segregation in circumferential direction strongly. However, the differences of relative charged mass of sintered ore in three nut coke conditions are quite a few, thus the condition of the nut coke position affects on the segregation of sintered ore little. On the other hand, the difference of mass of nut coke is significant large, hence the particle behavior during charging into the blast furnace will be discussed about two angular positions in the following section; i.e. the area under the damper (30-60 degrees) and the one between the damper (0-15 and 75-90 degrees).

\subsection{Analysis of Particle Charging Behavior into the Blast Furnace}

Figure 24 shows the snapshots of particle charging behavior into the blast furnace under Condition 1. The particles of coke layer at the top of blast furnace are pressed downward by the compressive force during charging. The smallest particles (the particle colors refer to Fig. 2) are segregated at the bell surface during discharging, and the relation between the volume flow rate, $q_{\mathrm{v}}$, for each kind of particle and the discharging time is shown in Fig. 25. $q_{\mathrm{v}}$ for smaller particles $(22.5$ and $37.5 \mathrm{~mm}$ ) have the peaks after all larger particles were discharged, because the space increases. After $8 \mathrm{~s}$, only the smallest particles are still discharging from the bell due to the size segregation on the bell surface. It is seen that some nut coke particles are discharged at the middle or later periods, although all of the nut coke positioned at the bottom of the quad-hopper. Thus, it is confirmed that the position of nut coke moved upward during traveling, as discussed in the previous section. Figure 26 shows the snapshot of cross section of charged bed, the dark gray particles are the coke particles of the layer in the blast furnace. It is found that the many sintered ore particles crept into the coke layer, especially smaller particles are significant due to the ease of percolating between the particles' space. Figure 27 shows the radial distribution of the specific charged mass of nut coke particles, $W_{\mathrm{s}}$. The distributions of the area under the damper (30-60 degrees) and the one between the dampers (0-15 and 75-90 degrees) are shown in this figure. $W_{\mathrm{s}}$ increased with increasing the radial distance, because the particles are charged at near the wall. The small peaks are seen around $L_{\mathrm{R}}=3.0$ in both conditions, these are caused by the particle segregation during
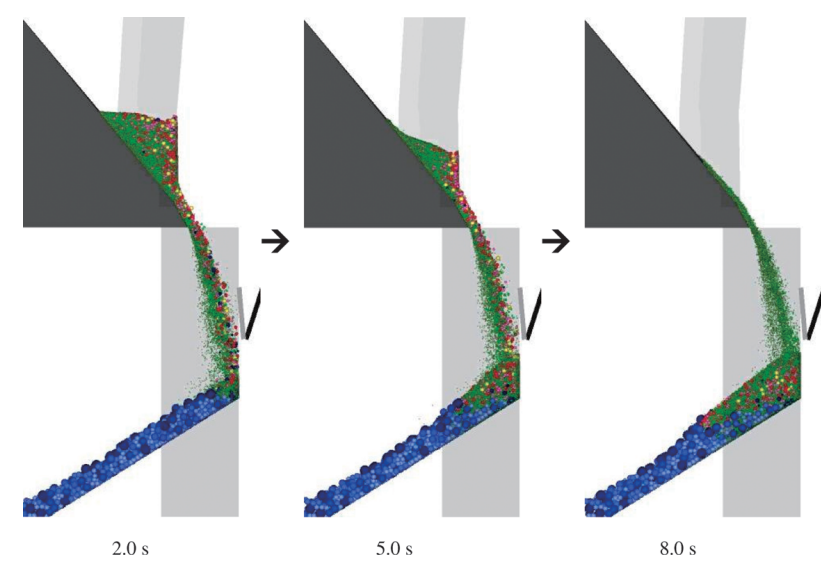

Fig. 24. Snapshots of particle charging behavior into the blast furnace. 


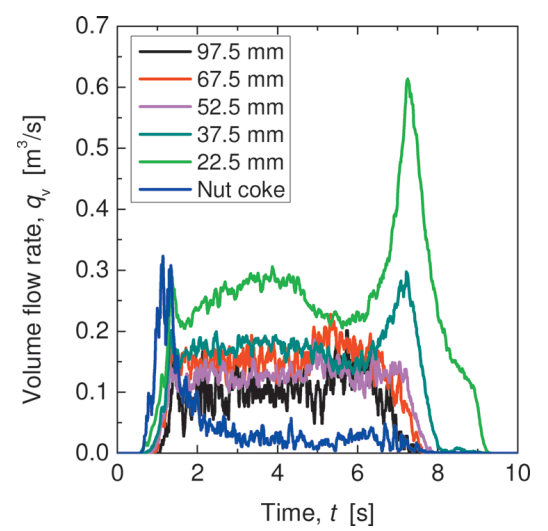

Fig. 25. Time changes of volume flow rate of the particles discharged from the large bell.

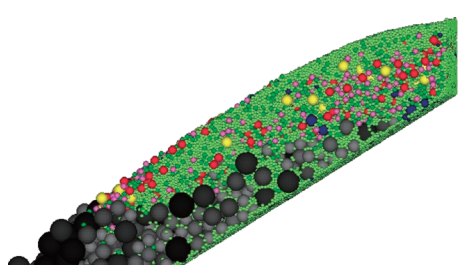

Fig. 26. Snapshot of cross section of charged bed under Condition 1.

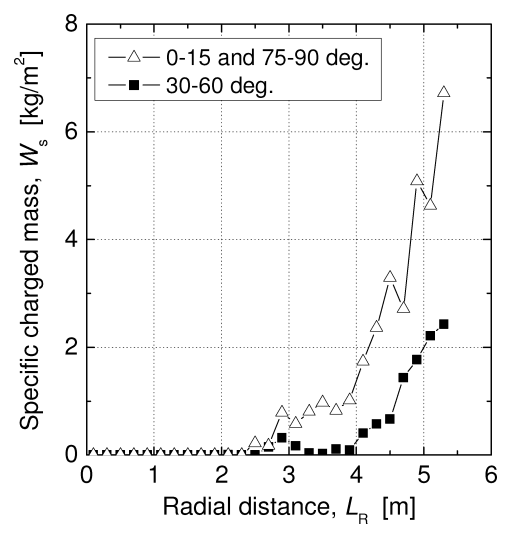

Fig. 27. Radial distribution of the specific charged mass of nut coke particles under Condition 1.

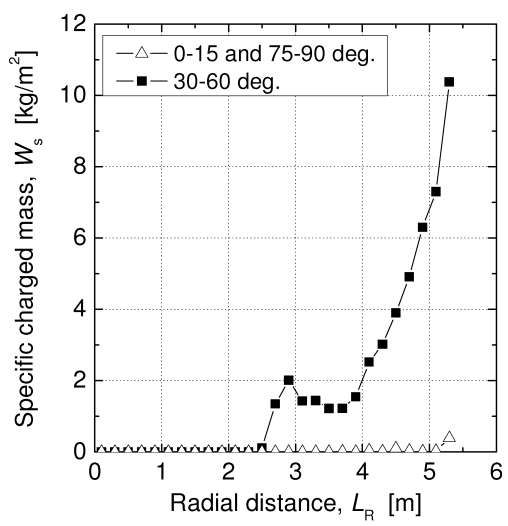

(a) Condition 2

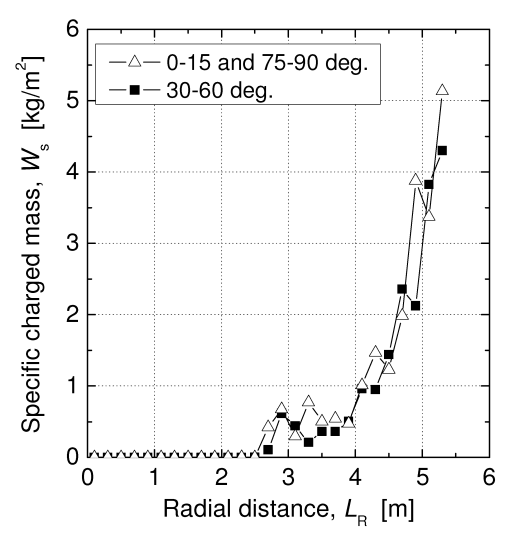

(b) Condition 3

Fig. 28. Radial distribution of the specific charged mass of nut coke particles.

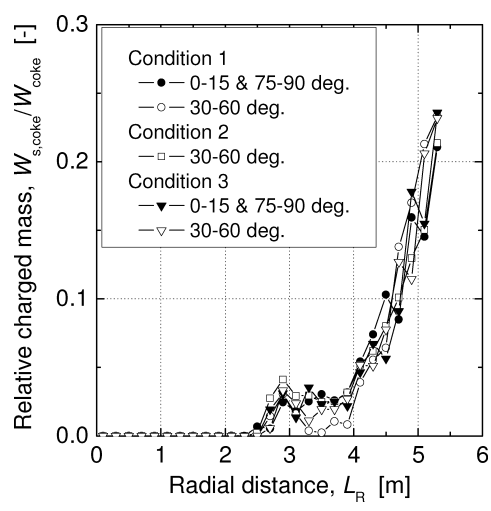

Fig. 29. Relation between the relative specific charged mass of nut coke particles and the radial distance.

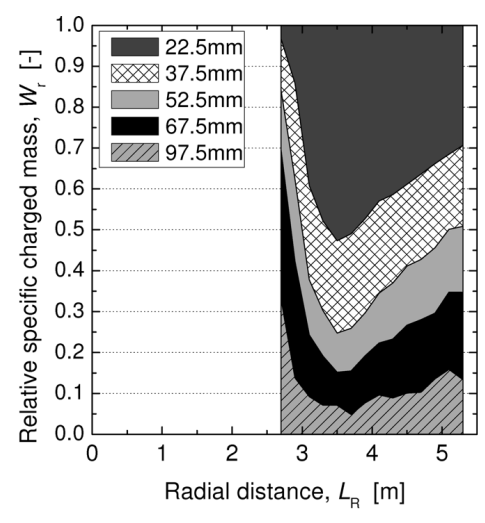

(a) Condition 1

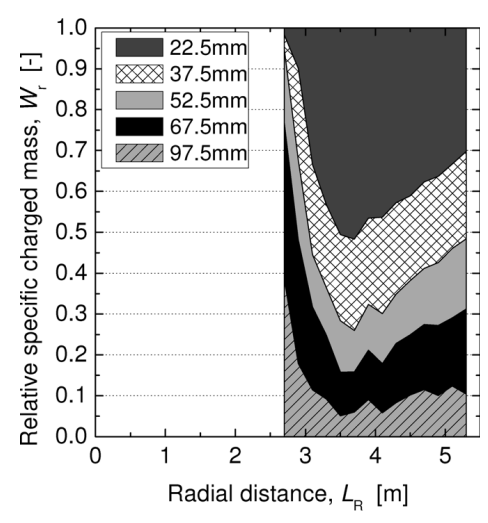

(b) Condition 2

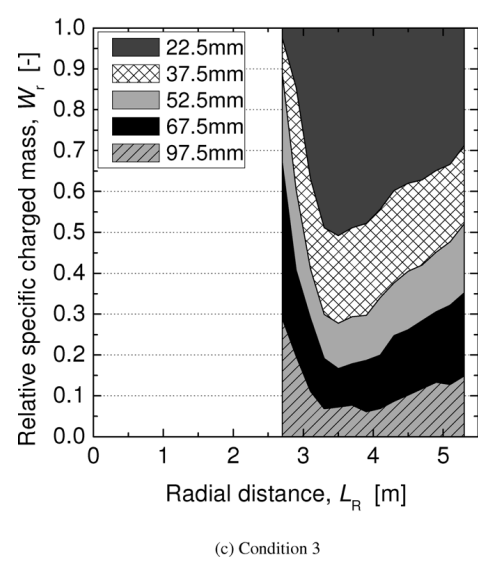

Fig. 30. Distribution of the relative specific charged mass of sintered ore particles in the area of 30-60 degrees. flowing on the particle bed. The density of nut coke is more than 3 times smaller than that of sintered ore, then the particles are easy to be segregated during flowing. The tendencies of the distribution for two areas are mostly same, although the mass of the nut coke particle is different (see Fig. 22). Figure 28 shows the radial distributions for other conditions. The one for $0-15,75-90$ degrees in Fig. 28(a) is almost zero, because the most of nut coke particles were positioned under the damper (see Fig. 22). Then, the values for 30-60 degrees are much larger than those of other conditions. Two distributions in Condition 3 are comparable, thus the angular fluctuation of the nut coke distribution can be minimized by charging the well-mixed nut coke from the quad-hopper. It is also found that the tendencies of the radial distributions are quite similar to those in Fig. 27, although the total mass of nut coke in each area are not same (see Fig. 22). Figure 29 shows the relation between the relative specific charged mass and the radial distance for five conditions, the data of 0-15 and 75-90 degrees for Condition 2 are not included. The relative specific charged mass was given by the normalizing the mass of nut coke particles at each radial position, $W_{\mathrm{s} \text {,coke }}$, by the total mass of nut coke of the area, $W_{\text {coke. }}$. It is noteworthy that all of the distributions give quite similar tendencies. Therefore, the nut coke segregation during charging into the blast furnace isn't affected by their positions in the large bell and the total 
mass, and the difference in the density between the nut coke and the sintered ore is more dominant than the history of traveling via the small and large bells. Figure 30 shows the distributions of the relative specific charged mass of the sintered ore particles, which were charged in the area 30-60 degrees. The peak of the smallest particle is around $L_{\mathrm{R}}=3.5 \mathrm{~m}$, because the falling point of the smallest particles is closer to the center of the blast furnace according to Fig. 24. The smallest particles were discharged from the large bell surface because of the size segregation during sliding, and lots of smallest particles came into the blast furnace at the latter period of the charging process (see Fig. 25 ), then the large bell went down completely at this period. Thus the smallest particles are charged at the area, which is close to the center. On the other hand, the larger particles are charged at near the wall because of size segregation during sliding. Hence, the fractions for larger particles are large at near the wall. The larger particles also have the large fraction at near the center; this is caused by the size segregation during flowing on the particle layer. This tendency is seen in all nut coke conditions, and the values for all sized particle are significant similar. Therefore, the condition of nut coke particle hardly affects on the segregation of the sintered ore particle.

The magnitude of the sintered ore particles' flowing toward the center seems to be less, some reasons might be thought. The first one is that the calculation area of this analysis was quarter of the blast furnace, and the walls were installed at the both sides. The particles had more interaction from the walls with moving toward the center. The second is that all of particle sizes were enlarged three times. Setting of the plate under the coke layer instead of the ore layer is another reason. These are the solutions of the reducing the computation load. Thus the speed-up of DEM is extremely important issue to improve the simulation of burden distribution.

\section{Conclusions}

In this paper, the bell-type charging process of actual blast furnace was modeled by using Discrete Element Method. The circumferential balance of charged mass in the quad-hopper, and the effect of nut coke position (top, bottom or mixed) in the quad-hopper on the traveling behavior were analyzed. The followings are summaries of this work.

(1) The mass flow rate from the rotating chute was fluctuated with chute rotation, and the peak values gave when the directions of the chute movement became same as the one of conveyor. Because the reduction of particle velocity at chute is less. This fluctuation leads to the unbalance of charged mass in each part of the quad-hopper.

(2) The nut coke position moved to the upward in the sintered ore particle layer during traveling to large bell from the quad-hopper due to the particle segregation, when they were segregated at the bottom of quad-hopper. However their relative positions moved downward when they were segregated at the top, because the time for starting discharging of nut coke became faster.

(3) The installation of the damper at the way to the small bell from the hopper affects on the circumferential balance of mass of nut coke. The nut coke particle positioned both side in the small bell, when they were segregated at the bottom of hopper, on the other hand, they were at under the damper when they segregated at the top.

(4) The sintered ore particles crept into the coke layer during charging into the blast furnace, especially the smaller particles were significant due to the ease of percolating between the particles' space.

(5) Most of nut coke particles were charged at near the wall, and the small peak of the distribution of its specific charged mass was seen around $3.0 \mathrm{~m}$ in radial distance from the center, it is caused by the particle segregation during flowing on the particle layer.

(6) The relative radial distribution of the nut coke particles wasn't affected by their positions in the large bell and the total mass. The difference of particle density is more dominant. Thus, keeping the circumferential balance of nut coke mass in the large bell is very important.

(7) The position of nut coke particle didn't affect on the segregation of sintered ore during charging to the blast furnace. The radial distributions of relative charged mass for all condition were quite similar.

\section{REFERENCES}

1) Y. Shimomura, Y. Kushima, F. Sato and S. Arino: Tetsu-to-Hagané, 62 (1976), S404.

2) K. Okuda, S. Amano, N. Ishioka, H. Ono, T. Furukawa and T. Inoue: Tetsu-to-Hagané, 69 (1983), S731.

3) M. Isobe, T. Sugiyama and S. Inaba: Proc. 6th Int. Iron Steel Cong., ISIJ, Tokyo, 2 (1990), 439.

4) S. Watanabe, K. Takeda, H. Nishimura, S. Goto, N. Nishimura, T. Uchida and M. Kiguchi: Tetsu-to-Hagané, 92 (2006), 901.

5) A. Babich, D. Senk and H. W. Gudenau: Ironmaking Steelmaking, 36 (2009), 222.

6) P. A. Cundall and O. D. L. Strack: Geotechnique, 29 (1979), 47.

7) T. Tanaka, Y. Kajiwara and T. Inada: Tetsu-to-Hagané, 74 (1988), 2262.

8) Y. Kajiwara, T. Inada and T. Tanaka: Tetsu-to-Hagané, 75 (1989), 235.

9) S. Matsuzaki and Y. Taguchi: Tetsu-to-Hagané, 88 (2002), 823.

10) H. Mio, S. Komatsuki, M. Akashi, A. Shimosaka, Y. Shirakawa, J. Hidaka, M. Kadowaki, S. Matsuzaki and K. Kunitomo: ISIJ Int., 48 (2008), 1696.

11) H. Mio, S. Komatsuki, M. Akashi, A. Shimosaka, Y. Shirakawa, J. Hidaka, M. Kadowaki, S. Matsuzaki and K. Kunitomo: ISIJ Int., 49 (2009), 479. 